\title{
Fungal Diversity in Droppings of Spot- Billed Pelican, Pelecanus philippensis
}

\author{
Kavitha N. and Zehra Amtuz* \\ PG and Research Department of Zoology, JBAS College for Women, 56 K.B Dasan Road, Teynampet, Chennai 600 \\ 018. Tamil Nadu, India
}

*Corresponding Author

Received: $26^{\text {th }}$ April, 2021

Accepted: 29th May, 2021

Published online: $2^{\text {nd }}$ June, 2021

\section{https://doi.org/10.33745/ijzi.2021.v07i01.020}

\begin{abstract}
Birds are potential vectors of some diseases as their droppings pose public health risk and cause illness. Dust containing dry faeces after inhaling can infects humans. The prevalence of fungi from the faeces of birds in wetlands has not been previously determined. Hence, the present study was carried out to isolate and identify different fungal species present in the droppings of spot-billed pelican, Pelecanus philippensis. Among the fungal species identified Aspergillus flavus, Aspergillus niger and Aspergillus fumigatus were found to be dominating.
\end{abstract}

Keywords: Opportunistic species, Mesophilic fungi, Acidophilic fungi, Alkaliphilic fungi, Airborne infections, Spotbilled pelican

Citation: Kavitha N. and Zehra Amtuz: Fungal diversity in droppings of spot- billed pelican, Pelecanus philippensis. Intern. J. Zool. Invest. 7 (1): 259-265, 2021. https://doi.org/10.33745/ijzi.2021.v07i01.020

\section{Introduction}

Birds are highly developed animals which are found worldwide in a variety of habitats. They are distinguished from other vertebrates by their adaptations for flight, including hollow bones, wings and feathers. One such adaptation is the excretion of uric acid. Birds have benefited mankind by serving as sources of food, cultural and religious symbols, sentinels of environmental hazards, large consumers of insects, pollinators of plants, and a source of companionship and enjoyment. From a public health perspective, birds pose little direct threat to humans compared to other vertebrates; however, it is important to be aware of the potential health and safety risks that contact with birds may pose. For certain diseases, birds are not the natural reservoir of disease causing agent, but bird faeces facilitate the growth of environmental organisms, and humans are 
infected from the environment. Birds faeces are the metabolic waste products or byproducts that are resulted from the digestion of food intake. Birds excrete faeces in the form of uric acid and hence it is referred as uricotelic organisms. High nutrient content of birds excrement provides an excellent sanctuary for potentially harmful organisms. Several billions of bacteria are present in faeces including pathogenic, non-pathogenic, normal flora and the opportunistic species (Adegunloye, 2006). Pathogens may render individuals at increased risk of infection, especially if the host immune status is compromised (Ghannoum Mahmoud, 2016). Faeces of birds has its own properties, it can be in the form of semi-solid or watery and the colour of the faeces varies among the species of birds, some are whitish, ashy and dark brown in colour. Nutrient composition of faeces varies with the type of the bird, the feed ratio, the proportion of the litter droppings, the type of the litter and the manure handling system. Faeces varies both in physical and chemical composition and the factors affecting are: types of the birds, number of birds/unit area, nutrient density of the feed, environmental factors and other managemental factors (Vest et al., 2004). Chemically the faeces is composed of water, nitrogen, phosphorus, potassium etc. These properties of the faeces support the growth of billions of microorganisms. It is rich in organic content and hence conditions the soil and enhances the growth of the microbes. It is moist and supports the growth of fungus and also becomes a suitable breeding ground for pestiferous flies like house flies, flesh flies, black garbage flies, biting stable flies etc. It is also odorous as it produces fatty acids such as butyric, valeric, capronic and caprylic acids (Adegunloye, 2006).

Pelicans are aquatic birds. Chennai is the only urban area in India where we can see the pelicans right in the city. The back waters at Muttukadu in ECR Chennai is a hot spot of pelicans. Pelican habitat includes coastal water mudflats, sand banks, salt pans, small scrubs, large inlands and especially large lakes. Pelecanus is considered the only genus within Pelecanidae family. Spot-billed pelican is breeding resident of India. Pelican is 125$152 \mathrm{~cm}$ long and weighs up to $4.1-6 \mathrm{~kg}$. It is white in colour with grey crest, hind neck and a brownish tail. The feathers on the hind neck are curly and form a grayish nope crest. The pouch is pink to purplish and has large pale spot, the sides of the upper mandible is also spotted. The tip of the bill is yellow to orange. Large number of birds degrade water quality (Grant et al., 2001). The impact of bird use of a wetland on environmental water quality was investigated in southern California. They identified birds faeces as a probable source of enterococcus in a tidal wetland. Likewise Salmonella have been detected in surface waters in Canada (Johnson et al., 2003; Gannon et al., 2004), along the Mediterranean coast (Baudart et al., 2000, Martinez-Urtaza et al., 2004; Touron et al., 2005) and the US Gulf coast (Goyal et al., 1977). Bird droppings do pose a public health risk and causes illness. Humans even become infected by inhaling dust containing dried faeces (Chang et al., 2004) Prevalence of fungi from the faeces of birds in wetlands has not been determined previously, hence, the present study aims at elucidating the diversity of fungi in the droppings of spot-billed pelican, Pelecanus philippensis. 


\section{Materials and Methods}

Sampling:

The droppings of the bird, Pelecanus philippensis were collected from the banks of brackish water in the east coast road near Tiruporur, Tamil Nadu, India. A total of 20 samples were collected at morning hours between $7.00 \mathrm{am}$ to $8.00 \mathrm{am}$. The samples were collected using a surface sterilized spatula and were placed in a sterile plastic bags. Samples were brought to laboratory and processed for studying the mycoflora.

\section{Culture Medium:}

Three different media were used for isolation of fungi for the purpose of studying Acidophilic, Mesophilic and Alkaliphilic mycoflora from the droppings of the bird--

- Potato Dextrose Agar (PDA) was used for studying the diversity of the Mesophilic fungi ( $\mathrm{pH}-5.6)$

- PDA amended with lactic acid and sterile sea water was used for studying the diversity of the Acidophilic fungi ( $\mathrm{pH}-4.5)$.

- PDA prepared using saline water was used for studying the diversity of theAlkaliphilic fungi ( $\mathrm{pH}-9)$.

\section{Dilution Plating Technique:}

Fungi was isolated using dilution plating technique, $0.1 \mathrm{~g}$ of bird dropping was taken in a flask containing $10 \mathrm{ml}$ sterile distilled water. The contents were shaken for $15 \mathrm{~min}$ in a mechanical shaker. Then $1 \mathrm{ml}$ of extract was transferred to all the 3 PDA media $(20 \mathrm{ml}$ in each petri dish) to isolate the mesophilic, alkaliphilic and acidophilic fungi. Streptopenicillin was added for the containment of bacterial growth. The plates were maintained in triplicates and were incubated at room temperature. Developing colonies were counted, isolated and identified after a period of 5-9 days of incubation. Isolated colonies were subjected to analysis as average cfu/g of faeces, \% contribution and Isolation frequency using the following formulae:

Average CFU/g of faeces $=$ Total CFU/g of a species in faeces

Total number of samplings

All the data represented as mean and standard deviation. Data were subjected to statistical analysis.

\section{Results and Discussion}

In the present study, a total of 13 species were identified, which includes Aspergillus fumigatus, Drechslera hawaiiensis, Monilia sitophila, Aspergillus flavus, Aspergillus japonicus, Rhizopus stolonifer, Aspergillus niger, Aspergillus flavipes, Geotrichum candidum, Fusarium sp., Curvularia lunata, non-spore and Yeast (Figs. 1-4). 13 species

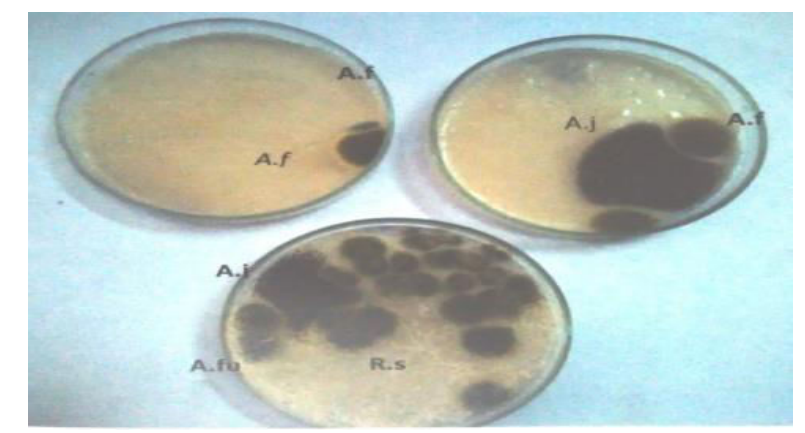

Fig. 1 : Photograph of culture plates showing growth of Aspergillus flavus( A.f), Aspergillus japonicas (A.j), Aspergillus fumigates (A.fu) and Rhizopus stolonifer (R.s).

belonging to 9 different genera were recorded as Mesophiles (Fig. 5). 11 species belonging to 8 different genera were recorded as Alkaliphiles (Fig. 6) and 5 species belonging to 3 different genera were recorded as Acidophiles (Fig. 7). Among the 13 species Aspergillus flavus, A. fumigatus and A. niger 


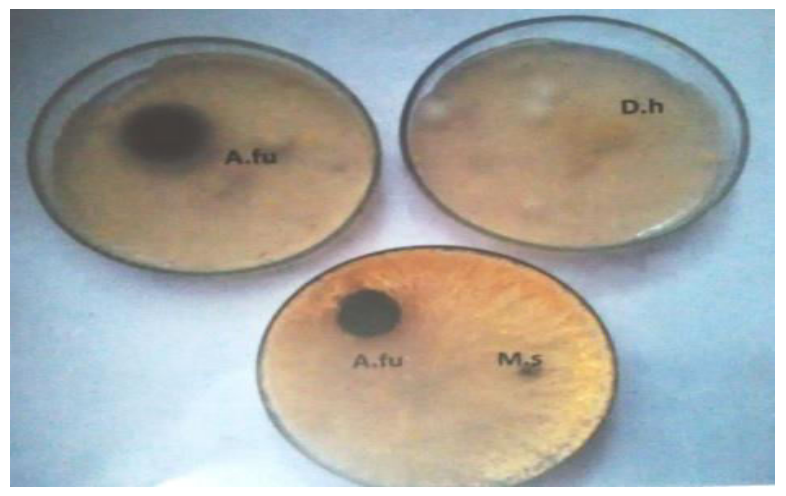

Fig.2: Photograph of culture plates showing growth of Aspergillus fumigatus(Afu), Drechslera hawaiiensis (D.h) and Monilia sitophila(Ms).

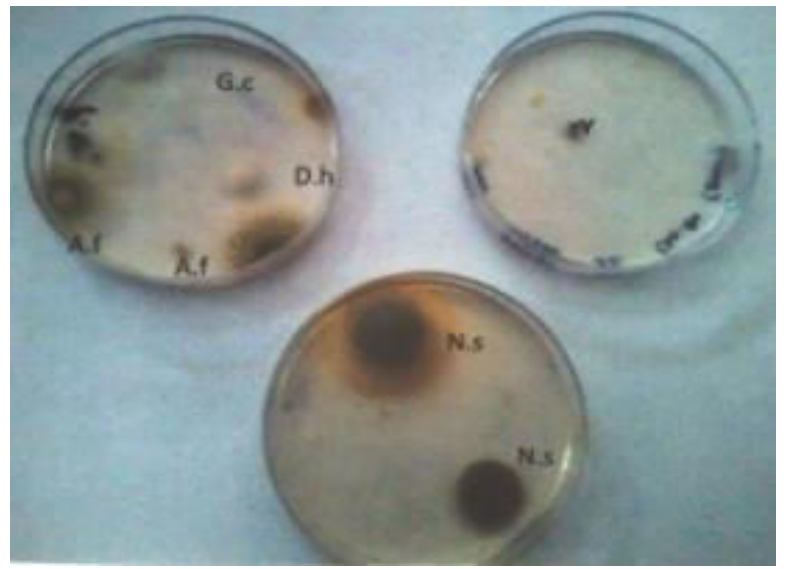

Fig. 3: Photograph of culture plates showing growth of Aspergillus flavus (A.f), Yeast (Y), Non-spore (N.s), Drechslera hawaiiensis (D.h) and Geotrichum candidum(G.c).

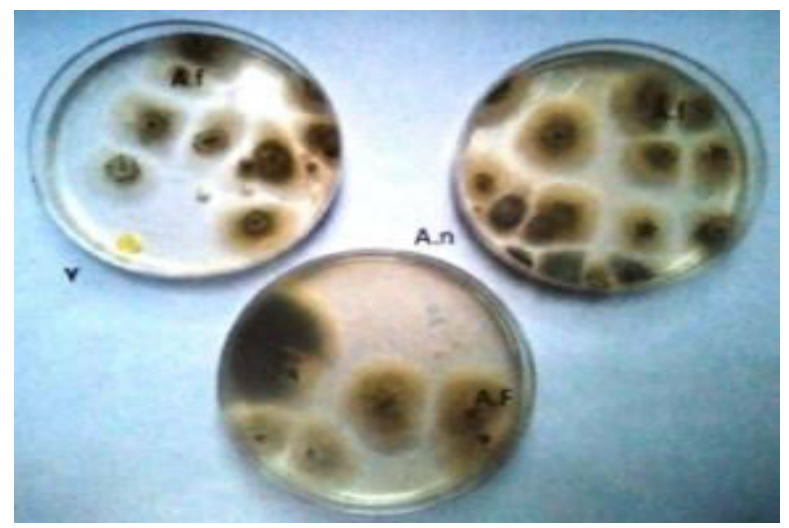

Fig. 4: Photograph of culture plates showing growth of Aspergillus flavus (A.f), Aspergillus niger (A.n) and Yeast (Y).

were found to be dominating. Aspergillus flavus is a saprotrophic, cosmopolitan and pathogenic fungi. It colonizes cereal grains, legumes and tree nuts. It produces toxic compounds known as mycotoxins (toxic to mammals). It is an opportunistic human and animal pathogen, causing Aspergillosis in immune-compromised individuals. Aspergillus niger causes a disease called Black mold on fruits and vegetables and is a contaminant of food, it forms black colonies. It produces a mycotoxin known as Ochratoxin $\mathrm{A}$ and Iso flavoneorobol. It causes Otomycosis which ia a fungal ear infection causing pain, temporary hearing loss, damage to ear canal and tympanic membrane. Aspergillus fumigatus fungal colony produces minute grey-green conidiophores $(2-3 \mu \mathrm{m})$ that readily become airborne. It causes Chronic pulmonary infections and allergic broncho-pulmonary aspergillosis. It infects lungs leading to morbidity and mortality. Live stock rely on water bodies. Birds roosting on water bodies contaminate the water(Alderisio and Deluca, 1999). Birds return the acquired pathogen via faeces to humans and other organisms through water (Reilly et al., 1981). Pathogens found in faeces originate from human sewage and are susceptible to infect when they reenter the human food chain. Sediments of faeces serve as the reservoir for pathogens (Obiri-Danso and Jones, 2000) and infect children who dig and play in wet sand. Water disturbs the sediment releasing faecal coliforms in to the overlying water (ObiriDanso and Jones, 1999) hence, increasing risk of contact for humans (Ksenija et al., 2010) Avian zoonoses are asymptomatic infection and increases the transmission of diseases to owners (Mancianti et al., 2002).Maintenance of hygiene like wearing gloves, washing and sanitizing hands will avoid possible transmission of avian zoonoses (Ritchie et al., 1994). 


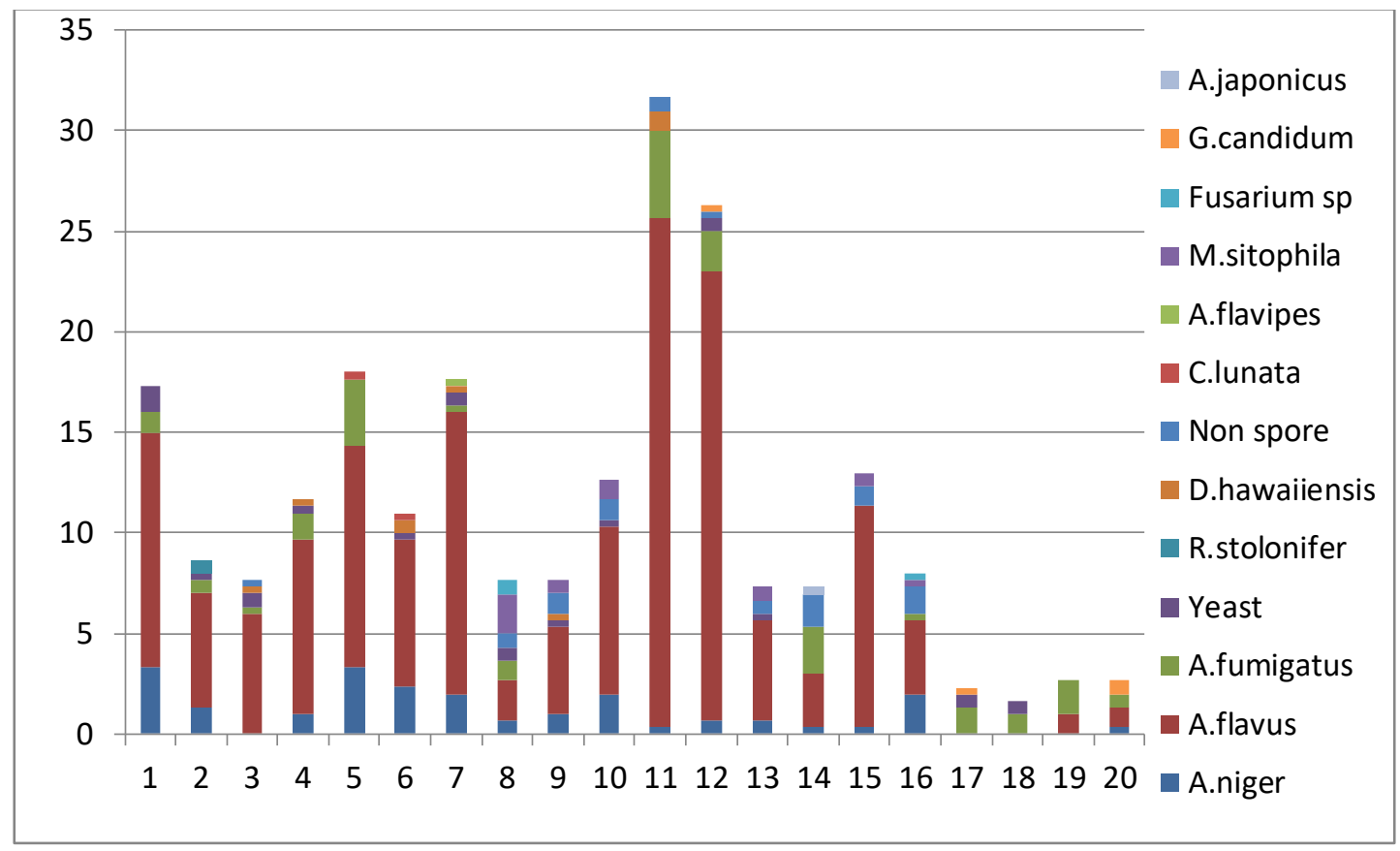

Fig. 5: Mesophilic fungus isolated from Pelican faeces.

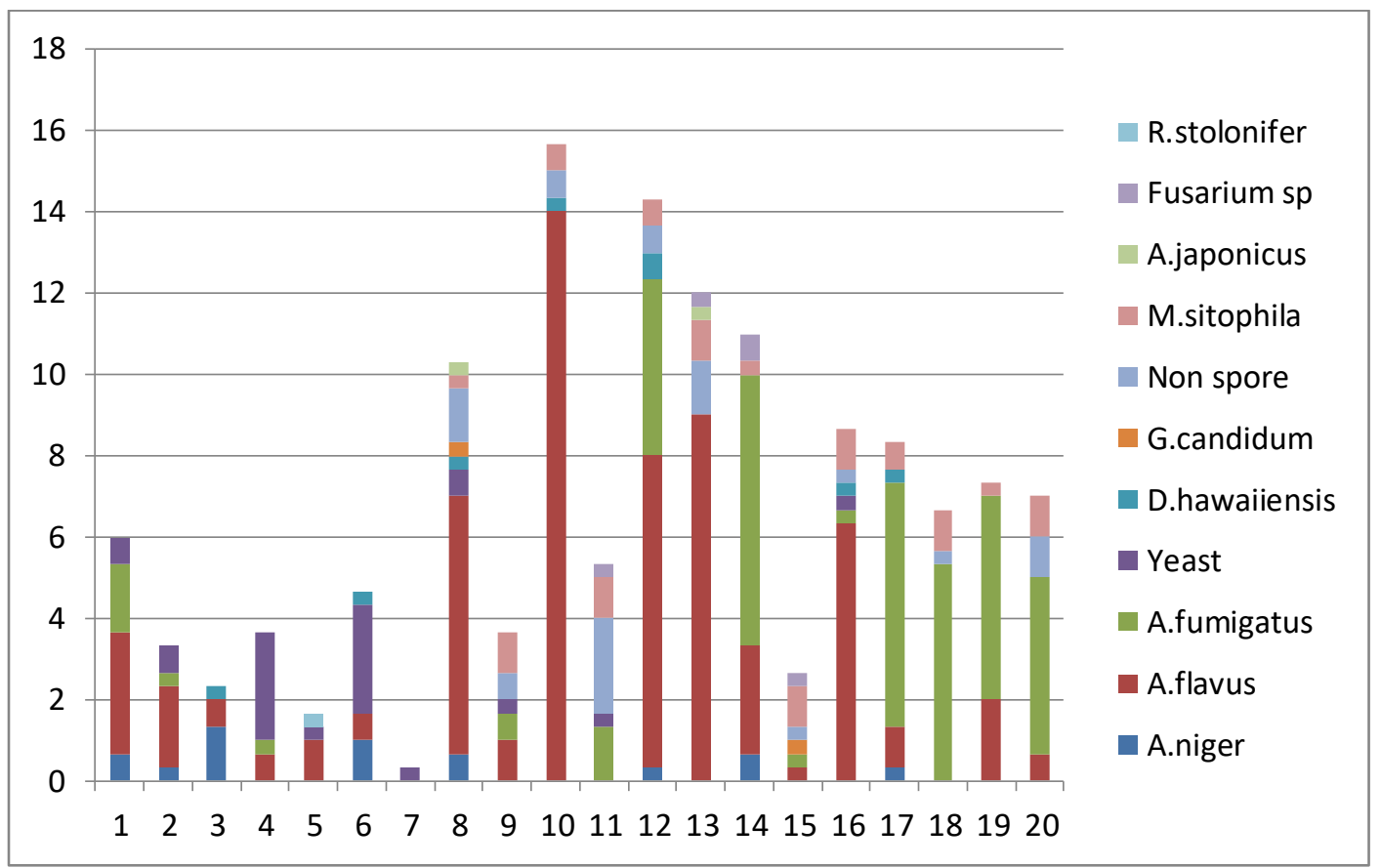

Fig. 6: Alkaliphilic fungus isolated from Pelican faeces. 


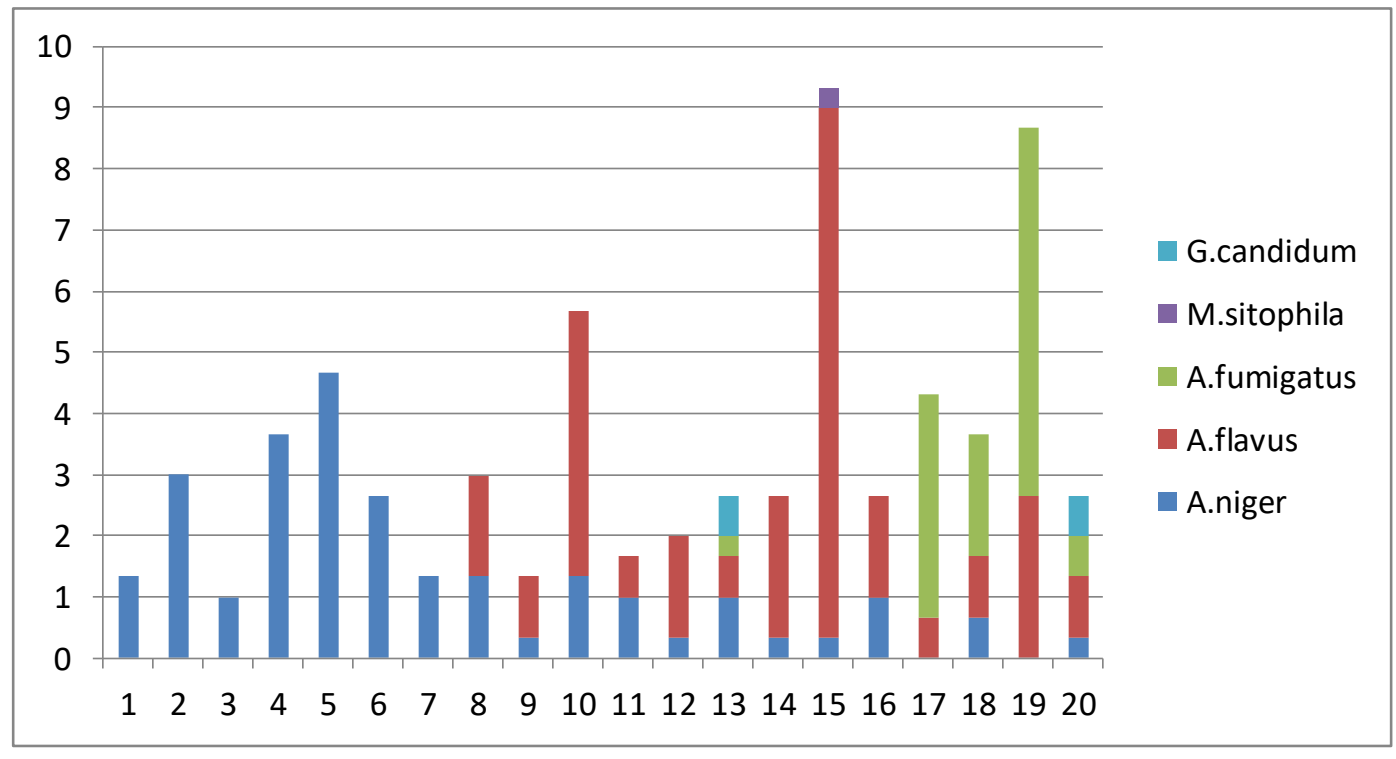

Fig. 7: Acidophilic fungus isolated from Pelican faeces.

\section{Conclusion}

Faeces play an important role in ecology and circulation of potential zoonotic Fungi isolated were found to induce cutaneous and systemic animal and human diseases. Safe and sanitary hygienic measures reduce the threat of diseases, when an individual comes in contact with Pelican habitat. Damage caused by the continued accumulation of pelican droppings need to be further investigated. Strategies for safe disposal of such droppings should be worked out to reduce fungal diseases and to provide an unpolluted aquatic ecosystem, which is safer for the species that survive and rely on water bodies.

\section{Acknowledgement}

The authors are thankful to the Management, JBAS College for Women, Chennai, India for providing the lab facilities for this work.

\section{References}

Adegunloye DV, (2006) Microorganisms Associated with Poultry Faeces. J Food Agricult Environ. 4: 41-42.

Alderisio KA and Deluca N. (1999) Seasonal enumeration of fecal coliform bacteria from the feces of ring-billed gulls (Larus delawarensis) and Canada geese (Branta canadensis). Appl Environ Microbiol. 65: 5628-5630.

Baudart J, Lemarchand K, Brisabois A and Lebaron P. (2000) Diversity of Salmonella strains isolated from the aquatic environment as determined by serotyping and amplification of the ribosomal DNA spacer regions. Appl Environ Microbiol. 66: 1544-1552.

Chang WN, Huang CR, Lei PY, Chein CC and Chang HW. (2004) Serotypes of clinical cerebrospinal fluid Cryptococcus neoformans isolates from Southern Taiwan and their in vitro susceptibilities to Amphotricin B, Fluconazole, and Voriconazole. Japan J Infect Dis. 57: 113-115.

Ghannoum M. (2016) The Mycobiome: The largely overlooked resident fungal community plays a critical role in human health and disease. Scientist. 2016. https://www.the-scientist.com/features/themycobiome-34129.

Goyal SM, Gerba CP and Melnick JL, (1977) Occurrence and distribution of bacterial indicators and pathogens in canal communities along the Texas coast. Appl Environ Microbiol. 34 (2):139-149.

Gannon VPJ, Graham, TA, Read S, Ziebell K, Muckle A, Mori J, Thomas J, Selinger, B, Townshend L and Byrne J. (2004) Bacterial pathogens in rural water supplies in southern Aberta Canada. J Toxicol Environ Hlth. 67: 1643-1653. 
Grant SB, Sanders BF, Boehm AB, Redman JA, Kim JH, Mrse RD, Chu AK, Gouldin M, McGee CD, Gardiner, NA, Jones, BH, Svejkovsky J, Leipzig GV and Brown A. (2001) Generation of enterococci bacteria in a coastal salt water marsh and its impact on surf zone water quality. Environ Sci Technol. 35 (12): 2407-2416.

Johnson JYM, Thomas JE, Graham TA, Townshend I, Byrne J, Sellinger LB and Gannon VPJ. (2003) Prevelance of Escherichia coli 0157:H7 and Salmonella spp. in surface waters of southern Alberta and its relation to manure sources. Can J Microbiol. 49: 326-335.

Ksenija V, Marina Tomislav G and Zdravka R. (2010) Bacterial and fungal flora in faecal sample from rooks (Corvus frugilegus) in the city of Zagreb, Croatia. Veterinarski Arhiv. 80: 81-92.

Mancianti F, Nardoni S and Ceccherelli R. (2002) Occurrence of yeast in psittacines dropping from captive birds in Italy. Myocpathol. 153: 121-124.

Martinez-Urtaza J, Saco M, de Novoa J, Perez-Pieiro P,Peiteado J, Lozano-Leon A, and Garcia-Martin 0. (2004) Influence of environmental factors and human activity on the presence of Salmonella serovars in a marine environment. J Appl Environ Microbiol. 70: 2089-2097.

Maria D, Anna B, Iwona K, Elzbieta E, Dariusz K and Ewa S. (2015) Epidemiological importance of yeasts isolated from the beak and cloaca of healthy Charadriiformes. Bull Vet Inst Pulawy 59: 65-69.
Obiri-Danso K and Jones K. (2000) Intertidal sediments as reservoirs for hippurate negative campylobacters, Salmonellae and faecal indicators in three EU recognized bathing waters in north west England. Water Res. 34: 519-527.

Obiri-Danso K and Jones K. (1999) The effect of a new sewage treatment plant on faecal indicator numbers, camphylobacters and bathing water compliance in Morecambe Bay. J Appl Microbiol. 86: 603-614.

Reilly WJ, Forbes GI, Patterson GM and Sharp JC. (1981) Human and animal salmonellosis in Scotland associated with environmental contamination, 1973-79. The Vet Rec. 108: 553-555.

Ritchie BW, Harrison, GJ and Harisson LR. (1994) Avian medicine: Principles and application, Wingers Publishing, Inc., Lake Worth, Florida.

Touron A, Berthe T, Pawlak B and Petit F. (2005) Detection of Salmonella in environmental water and sediment by a nested multiplex polymerase chain reaction assay. Res Microbio. 156: 541-553.

Vest L, Merka, B and Segars WI. (2004) Composition of Poultry Waste. The University of Georgia, Georgia College of Agric and Environmental Sciences, Athens. 